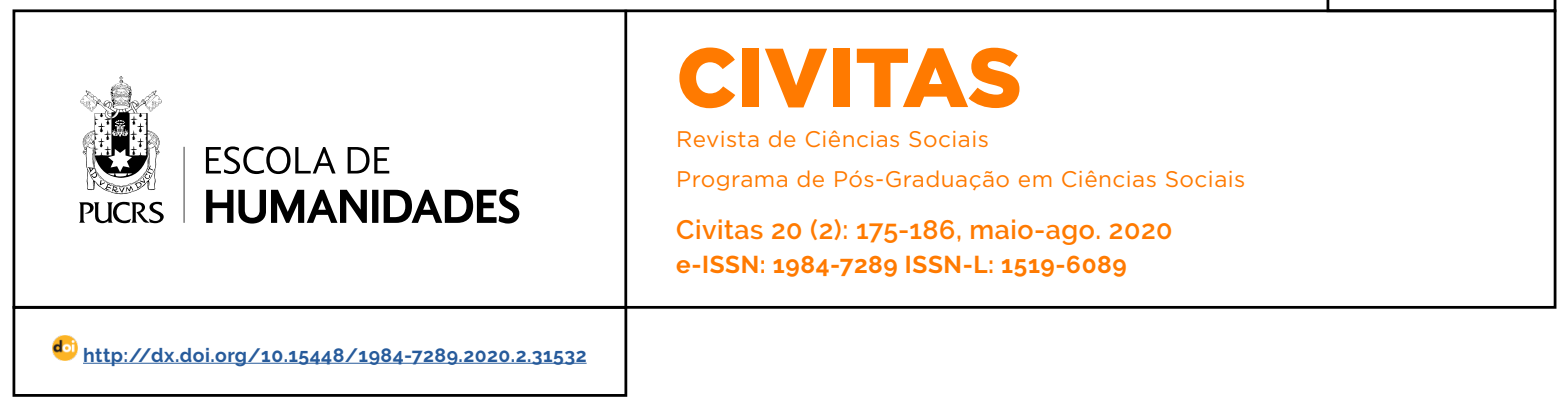

\title{
As duas maiores papeleiras do mundo e seus cativeiros de papel: reflexões sobre o caso de um assentamento localizado no Bolsão Sul-mato-grossense
}

\author{
The two biggest paper's factories of the world and their paper's cages: reflections on \\ the case of a location in Mato Grosso do Sul state bags \\ Las dos papeleras más grandes del mundo y sus prisiones de papel: reflexiones sobre \\ el caso de una posesión rural ubicado en el bolsillo del Mato Grosso do Sul
}

\section{Cláudio Ribeiro Lopes ${ }^{1}$ \\ orcid.org/0000-0002-3916-0322} claudiolopes198@gmail.com

\author{
Napoleão Miranda² \\ orcid.org/0000-0003-2319-2167 \\ napomir@gmail.com
}

Recebido em: 27 jul. 2018. Aprovado em: 9 mar. 2020 Publicado em: 4 ago. 2020

\section{(c) (1)}

Artigo está licenciado sob forma de uma licença Creative Commons Atribuição 4.0 Internacional.
Resumo: A incidência de indústrias papeleiras na região de Três Lagoas, a partir de 2009, trouxe uma série de compromissos e consequências aos assentados da reforma agrária. Com a oferta de isenções fiscais ilimitadas, financiamento público via BNDES e outros programas e projetos de fomento industrial, as indústrias se estabeleceram e iniciaram os processos para duplicação de suas plantas industriais. Já, os assentados ficam à mercê, pois, não têm condições de obter acesso a investimentos, nem a financiamentos dos bancos públicos e demais agências de fomento. Nessa perspectiva, a única fonte de financiamento da produção agricola familiar acaba sendo as próprias papeleiras, por meio de seus planos e programas de desenvolvimento sustentável (PDS). Apenas no assentamento onde se desenvolveu a empiria há 181 lotes, mas, menos de 20 foram beneficiados pelos financiamentos. Nesse sentido, a forma e o modelo de financiamento, a velocidade e o volume de recursos aportados ficam à discricionariedade absoluta e exclusiva das próprias papeleiras, o que repercute social e economicamente entre os assentados, criando como que uma zona de aprisionamento dos assentados às papeleiras, aqui denominadas cativeiros de papel.

Palavras-chave: Capitalismo. Expropriação. Estado. Políticas públicas. Cativeiros de papel.

Abstract: The incidence of paper mills in the Três Lagoas region, as of 2009 , brought a series of commitments and consequences to the settlers of the agrarian reform. With the offer of unlimited tax exemptions, public financing through BNDES and other industrial development programs and projects, the industries established and started the processes for the duplication of their industrial plants. Already, the settlers are at the mercy, therefore, can not obtain access to investments, nor to the financing of public banks and other development agencies. In this perspective, the only source of financing for family agricultural production ends up being the paper mills themselves, through their PDS - sustainable development plans and programs. Only in the settlement where the research was given there are 181 lots, but less than 20 were benefited by the financing. In this sense, the form and the model of financing, the speed and volume of resources contributed are at the absolute and exclusive discretion of the own pulleys, which has social and economic repercussions among the settlers, creating as a zone of imprisonment of the settlers to the paper, here called cages of paper. Keywords: Capitalism. Expropriation. State. Public policy. Cages of paper.

Resumen: La incidencia de industrias papeleras en la región de Três Lagoas, a partir de 2009, trae serie de compromisos y consecuencias a los asentados de la reforma agraria. Con la oferta de exenciones fiscales ilimitadas, financiamiento público vía BNDES y otros programas y proyectos de fomento industrial, las in- 
dustrias se establecieron e iniciaron los procesos para duplicación de sus plantas industriales. Ya, los asentados se quedan a merced, pues, no tienen condiciones de obtener acceso a inversiones, ni a financiamientos de los bancos públicos y demás agencias de fomento. En esta perspectiva, la única fuente de financiamiento de la producción agrícola familiar termina siendo las propias papeles, a través de sus PDS - planes y programas de desarrollo sostenible. Sólo en el asentamiento donde se dio la encuesta son 181 lotes, pero menos de 20 fueron beneficiados por las financiaciones. En este sentido, la forma y el modelo de financiamiento, la velocidad y el volumen de recursos aportados quedan a la discrecionalidad absoluta y exclusiva de las propias papeles, lo que repercute social y económicamente entre los asentados, creando como una zona de encarcelamiento de los asentados a las papeleras, aquí denominada cadenas de papel.

Palabras clave: Capitalismo. Expropiación. Estado. Políticas públicas. Cadenas de papel.

\section{Introdução}

O processo agroindustrializante submetido ao Brasil nas últimas décadas e, em especial, ao Mato Grosso do Sul, é revelador de uma tomada de sentido com relação à reprodução do espaço territorial e dos meios inerentes à produção, com consequências socioambientais graves, como um todo. Não por outro motivo é possivel se estabelecer relações entre terra e poder. Desde muito se conhece que a distribuição histórica das terras no Brasil se deu tendo por pano de fundo o capital mercantil.

Nesse sentido o problema que se coloca diz respeito a como a entrada das papeleiras Fibria, atual Suzano e Eldorado Brasil na região leste do Mato Grosso do Sul, conhecida como Bolsão, serve não apenas para continuar a reproduzir o modelo de expropriação e concentração econômica e fundiária, muito difundido no País, desde o período colonial, mas, sobretudo, durante e a partir das duas décadas de ditadura empresarial-militar e, principalmente, como os processos e políticas pública e privada se combinam para manter os assentados da reforma agrária em uma condição de dependência exclusiva dos programas e planos de financiamento da produção agrícola familiar fomentados pelas próprias papeleiras na região.

Objetiva-se, portanto, apresentar como esse processo de aprisionamento socioeconômico dos assentados de um assentamento sito à região leste do Mato Grosso do Sul foi gestado e de que forma ele é operado, contando com a participação e omissão dos poderes públicos e a ação direta das indústrias papeleiras.

A metodologia para o trabalho consistiu em duas visitas ao campo: a primeira delas mais prolongada, com vinte e três dias em completa imersão na região de Três Lagoas, durante o mês de julho de 2015, o que incluiu a ida ao assentamento e a entrevista direta com assentados dali, bem como, outras entrevistas com vários outros sujeitos, envolvidos no processo - Secretaria Municipal de Meio Ambiente, Agronegócio e Tecnologia de Três Lagoas, Instituto de Meio Ambiente de Mato Grosso do Sul (Imasul), Sindicatos Rural e de Trabalhadores Rurais de Três Lagoas, indústria papeleira Eldorado Brasil, Instituto Nacional de Colonização e Reforma Agrária (Incra) - , ou, que possam estar, de alguma forma, questionando-o, como é o caso do Ministério Público Federal (MPF), da Procuradoria de Três Lagoas, MS, do Ministério Público do Trabalho (MPT) e do Ministério Público do Estado de Mato Grosso do Sul.

Posteriormente, em dezembro do mesmo ano, foram feitas outras visitas, mais céleres, para reentrevistar ao representante do MPF e entrevistar a do Instituto Brasileiro do Meio Ambiente (Ibama). Sobre a indústria papeleira Fibria (atualmente, Suzano), esta, de princípio, aceitou conceder a entrevista, mas, à véspera cancelou o contato.

Em outro momento, isto é, em janeiro de 2016 , procedeu-se a um registro de inconformismo junto ao programa Ethics-Point, uma espécie de ombudsman da indústria. Em cerca de vinte dias, deu-se a resposta, positiva, por parte do gerente nacional de sustentabilidade da papeleira, no sentido de acolher meu pedido e fornecer os dados que desejava colher durante a entrevista, o que possibilitou melhorar a qualidade do que me propus a investigar, já que, dessa forma, ambas as papeleiras foram não apenas pesquisadas, mas, sobretudo, puderam falar à pesquisa.

O resultado principal da pesquisa foi a identificação de um modelo político-negocial de aprisionamento dos assentados, não somente no assentamento onde se deu a empiria, ao que parece, ao financiamento da produção agricola familiar exclusivamente, ou quase, a programas e planos 
de desenvolvimento sustentável das próprias papeleiras, cujo volume de recursos e número de assentados e lotes atendidos fica à mercê da discricionariedade das indústrias de celulose e papel, o que se denomina, aqui, por cativeiros de papel.

Essa percepção de mundo que o resultado da pesquisa alcançou pouco antes da ruptura decorrente do último impeachment tende a se mostrar ainda mais complexa em virtude do cenário político nacional no Brasil contemporâneo, em que há evidentes sinais de completo menoscabo quanto à justiça social no campo e mesmo sobre o tema do campesinato e da agricultura familiar em detrimento do incremento ainda mais intenso das políticas públicas beneficiadoras ao capital agroindustrial.

\section{Aurora das papeleiras e o falso mantra da prosperidade infinita}

A ocupação, a incorporação e a apropriação do solo brasileiro têm obedecido à lógica expropriatória da privatização, que guarda relação direta com o fenômeno territorial-empresarial-financeiro-especulativo, isto é, ao modelo de apropriação mercantil-capitalista, ou, no sentir de Porto-Gonçalves e Cuin (2013, 18), um "bloco de poder tecnológico-financeiro-latifundiário-midiático". Terra é poder e quem a possui só a possui porque precede em recursos, sejam eles econômicos, políticos, tecnológicos, enfim. Nesse sentido, pode-se afirmar que há espaços de comando e espaços de subserviência (Santos e Silveira 2002, 264-265) que entremeiam essas relações sociais.

As complexas relações de poder estabelecidas em decorrência do modelo de funcionamento socioeconômico e que encontram na concentração fundiária e na detenção tecnológica dos meios de produção, aliadas à manipulação da representação política e midiática pelo mercantilismo capitalista formam o caldo de cultura que estabelece o rito de passagem para a perspectiva de uma sociedade que pouco enxerga a dominação e, mesmo visualizando-a, tende a acatar o mecanismo como inerente à própria condição existencial, naturalizando-a a partir do senso comum, em detrimento de sua própria condição, qualidade de vida e, mesmo, reprodução biossociocultural.
Nesse sentido, vários atores sociais desenvolvem a percepção de que não há conflitos ali, mas, apenas, problemas ambientais, sociais, ou, socioambientais, como restou identificado a partir de alguns sujeitos da pesquisa entrevistados.

Diante da perspectiva posta é possivel, inicialmente, inferir as relações dialéticas que suportam o objeto deste artigo, a saber, o problema espacial e dos mecanismos de controle espaço/ economia e as tensões que dai decorrem (isto é, a raiz do problema como sendo a concentração da ocupação e o uso do solo e as variadas formas de manifestação e controle social-econômico-normativo podem servir como fatores exponenciais de geração de conflitos socioambientais). Nesse sentido, surge a questão do campo dos conflitos socioambientais decorrentes "do uso e apropriação do território e dos elementos sociais, bióticos e abióticos do espaço" (Costa e Braga 2004, 195-196) como arena de situação da justiça ambiental como mais um elemento caracterizador das discussões em torno da legitimação ou não de determinadas práticas e modelos sociais.

Acolhe-se, aqui, alguns conceitos elementares, como aquele empregado por Acselrad, que identifica o campo dos conflitos socioambientais a partir da alusão a quatro dimensões em sua constituição: "apropriação simbólica e apropriação material, durabilidade e interatividade espacial das práticas sociais" (Costa e Braga 2004, 23-27).

É justamente a partir dessa perspectiva acoLhida que se defende a ideia de que o campo desta pesquisa, muito embora enxergue apenas a vivência de problemas ambientais, os quais submetem a acordos simbióticos (Acselrad 2004, 25), está inserido em uma condição de conflitos socioambientais, pois, evidenciam-se a presença de atores e de momentos de apropriação material da base de recursos (acesso a terras férteis, à água, à logística para escoamento da produção etc.) como um fator decisivo para a manutenção da agricultura familiar originária de projetos da reforma agrária na região de Três Lagoas, MS, em posição dialética com o latifúndio agropecuário e a monocultura de eucalipto que ali se instalou a partir do início do século 21. 
Por outro lado, essa apropriação não se apresenta isolada, mas, concomitante, ou, precedentemente, há a apropriação simbólica, que se evidencia nos valores sociais (renda da terra que deveria ser desconcentrada pela continuidade de projetos de reforma agrária naquele contexto e, para cujo implemento, o sucesso dos assentamentos funcionaria como a certificação de que os projetos dão certo, realizam-se e dão, concretamente, função social à terra), ambientais (a agricultura familiar sob modelo orgânico, com a reprodução de práticas sustentáveis no sentido de preservação da terra, das matas, da fauna, dos mananciais d'água etc.), políticos, visto haver clara tendência ao total abandono pelo atual governo do campesinato e da agricultura familiar, com evidentes sinais de favorecimento ao agronegócio.

Nesse sentido, além dessas apropriações destacadas, as questões atinentes à durabilidade dos valores de uso por parte dos assentados em detrimento dos valores de troca das papeleiras também se apresenta na relação, assim como, a interatividade entre os atores sociais, muita vez realizada sob o formato de acordos simbióticos (entre os assentados e as papeleiras, por exemplo, para a produção de alimentos orgânicos e que podem ser percebidos como estratégia de resistência por parte dos assentados frente ao capital agroindustrial), ou, mediante o confronto que se dá entre aqueles e o Instituto Nacional de Colonização e Reforma Agrária (Incra) e a Agência de Desenvolvimento Agrário e Extensão Rural (Agraer), quanto à recusa ao atendimento às necessidades burocrático-fundiárias e de tecnologias de consultoria ambiental e de agricultura.

Por isso, defende-se, aqui, que se lida, na realidade, com conflitos socioambientais e não meramente com problemas, ainda que a visão de atores sociais no campo ainda não tenha atingido esse nível de especificação ou de ação. O sentido racional do modelo é apropriar para gerar ainda maior apropriação; invisibilizar para gerar ainda mais condições de invisibilidade dos conflitos, afinal, essa racionalidade necessita salvaguardar-se, sistematicamente.
Porém, a perspectiva de que se partiu foi de que as relações sociais são conflitivas, em essência. Isso se exacerba num regime de produção capitalista, onde poucos efetivamente encontram acesso aos benefícios do sistema social, com ênfase à produção e distribuição de riqueza, à custa, inclusive de interferências nocivas à sociedade e, principalmente, ao ambiente cujas consequências sempre são difusas, dificultando, inclusive, a apuração posterior das responsabilidades, ante os fatos de degradação socioambientais.

O processo capitalista de produção, ontologicamente, é acumulativo (Marx 1987, 249); isso significa que em seu afã de apropriação da natureza, de riquezas, de concentração de renda, recursos e capital (principalmente a concentração fundiária sob o modelo monocultural) fundado, principalmente, na acumulação por despossessão (Brandão 2010, 41; Harvey 2014, 121) historicamente produz menoscabo significativo dos meios de vida, da realização social, cultural, produtiva e do convívio com o ambiente nas áreas em que se instala, sujeitando a população às mazelas ambientais e sociais do perverso lado da exploração mercantil.

Nessa perspectiva a expressão "conflitos distributivos e divida ecológica" (Martínez Alier 2014. 78-79) pode ser apropriada pelo discurso de enfrentamento do modelo imposto para marcar e acentuar que determinados investimentos promovem prejuizos ao meio ambiente e são, sim, fatores inexoráveis de degradação das condições de vida e relacionamentos sociais e ambientais no planeta, ainda que isso tudo venha sendo feito tendo como pano de fundo a utilização de um complexo sistema de propaganda que apregoa o "progresso", o "desenvolvimento" e uma determinada noção de "sustentabilidade", com o apelo, principalmente, às mídias nacional e local (Cirillo 2015, capa; 30-373; Minini 2015, 44604) para invisibilizar conflitos.

Nesse sentido, o conceito de passivo ambiental se apresenta recolocado no cenário social como mais um elemento caracterizador da exposição de um interesse que não se restringe, apenas,

\footnotetext{
Cirillo, Bruno. 2015. Lucro na floresta. Globo Rural, n. 357 (15 mar. 2015): 30-37. http://biblioblogfacig.blogspot.com/2015/07/revista-globorural-julho-2015.html.

4 Minini, Sarah. 2015. Indústria florestal: superação de crises desde a primeira semente. Revista Expressão MS, 2 jun-jul, 2015,7 : 44-60.
} 
à questão do controle sobre a produção, mas, que perpassa essa ideia para abarcar as possibilidades de alusões às externalidades negativas como mensuráveis e dignas de reparação a partir da ambientalização de determinados conflitos sociais (Lopes 2004, 216-222).

Nessa linha pode-se identificar um campo de disputas pela pregação da legitimidade da detenção, manipulação, exploração e manutenção do território e dos modos sociais de apropriação do mundo material com vistas a gerar acordos simbióticos que visem a naturalizar as externalidades negativas decorrentes da práxis dessa relação (Acselrad 2004, 16-17).

A própria construção da noção de sustentabilidade engendra uma série de conflitos em seu processo de estruturação, que vão desde a lógica malthusiana de racionalização dos recursos, passando pela lógica da gestão burocrático-estatal do patrimônio natural, até aos modelos de inclusão das noções culturais e de justiça ambiental como fundamentadores/legitimadores dos discursos propostos.

Nessa perspectiva é relevante a necessidade de construção de uma outra racionalidade ambiental como um meio de resgate, re-apropriação e re-tomada de uma forma de a sociedade se relacionar com o ambiente, isto é, de construir outra noção de sustentabilidade que vá além do economicismo, isto é, que seja capaz de superar a racionalidade do capital (Leff 2006, 248-249), que possa ser um contraponto à transformação do espaço e do território em "mera plataforma de valorização financeira internacional" (Paulani 2008, 41), principalmente, se pretende-se fazer frente, com algum nivel de tensão e visibilidade, ao modelo exploratório que foi imposto à cidade e região de Três Lagoas, MS e que obedece ao regime de flutuação das commodities internacional no segmento papel-celulose. Este desafio, portanto, exige que se estabeleça uma crítica estrutural; que sejam postos às claras os fatores de degradação socioambientais ali, bem como, os discursos que engendram a cobertura e a legitimação do modelo imposto como único possivel e viável, ou, como a panaceia liberal econômico-trabalhista-social- -ambiental do momento e para o futuro.

Exige que sejam visibilizados os conflitos socioambientais muitas vezes escamoteados, escondidos, jogados sob o tapete discursivo dominante que midiatiza o progresso, o desenvolvimento, uma dada sustentabilidade e os discursos da burocracia estatal, de políticos, empresários e, até mesmo, do senso comum, disseminado - não sem coerência, nem, propósito - com o fito de se assegurar o mínimo de resistência possivel contra o modelo, ou, até buscar demonstrar que essa resistência existe e apresenta modos próprios de sobrevivência e enfrentamento.

O processo de acumulação de capital, de concentração de renda e recursos (principalmente a concentração fundiária sob o modelo monocultural) tende a produzir menoscabo significativo nas áreas em que se instala, sujeitando a população às mazelas ambientais, econômicas e sociais do perverso lado da economia de mercado que, no Século 21, ganha contornos mais vorazes em razão da Globalização e os compromissos, públicos e privados, com o mercado internacional de commodities que ela suscita, sujeitando os estados nacionais ao direcionamento exigido para a manutenção do modelo pelos grandes agentes do sistema de produção - empresas multi e transnacionais, bancos, órgãos gestores etc. (Furtado 1974, 33). Os conflitos socioambientais, portanto, surgem em meio a essa dinâmica da sociedade, que pode, até, apresentar mesmo uma pequena parcela de pessoas ciente dos processos e prejuizos com os quais se vê obrigada a conviver, como parece ser - caso da cidade e região de Três Lagoas, Mato Grosso do Sul (Scotto e Vianna 1997, 25-28).

Nessa linha de raciocínio inquieta perceber que o processo agroindustrializante da monocultura de eucalipto e o complexo territorial celulose-papel na borda leste do Mato Grosso do Sul se impõem em conjunto com políticas e legislações, principalmente do setor público, a amparar os processos de degradação ambiental mediante a concentração fundiária, uso indiscriminado de agrotóxicos, dispensa de estudos de impactos ambientais pelos governos estadual e municipal, contrariando a norma federal, enfim. 
Explica-se mais detidamente: evidencia-se um quadro social que escapa ao controle normativo do Direito, uma vez que as normas que poderiam, em tese, ser aplicadas no caso em questão existem, mas, os agentes escapam ao seu campo de incidência usando o próprio Direito, criando, assim, como que uma terra de ninguém, em que a impunidade se revela como a regra maior e como a essência da lógica do sistema expropriatório socioeconômico. Trata-se não de uma impunidade que se situa à margem do sistema, mas, que se insere no sistema, usando o próprio Direito para criar situações de implícitas imunidades, esvaziando, assim, a capacidade de a norma e o Direito realizar um controle social com vistas a preservar os valores mais elevados e custosos à dignidade humana, como a proteção do ambiente, por exemplo.

A identificação dos fenômenos de concentração fundiária compreendidos na aquisição ou arrendamento de extensas áreas no bolsão sul-mato-grossense e econômica (duas indústrias instaladas no municipio de Três Lagoas que entraram em funcionamento em 2009 e 2012, respectivamente, para a produção de pasta de celulose atingiram a marca de 3.5 milhões de tonelada/ ano) dá o tom do ritmo capitalista avassalador ali desenvolvido. Em 2009, já se tinha notícia de que 2 milhões de hectares estavam plantados com os clones de eucalipto para fins industriais no Pais. ${ }^{5}$ Apenas em área plantada (ocupação maciça e concentrada do solo), a Eldorado Brasil chegou ao final de 2013 a 160.000 hectares; $^{6}$ a Fibria já alcançou a marca de 154.000 hectares, antes mesmo de findar-se o ano de 2013. Juntas, ambas as indústrias produzem 35 milhões de mudas de clones de eucalipto/ano. ${ }^{7}$ Trata-se de um modelo empresarial-político-negocial que nasceu para não encontrar limites. Nem mesmo a Resolução Conama (Conselho Nacional do Meio Ambiente) n. $237 / 97^{8}$ normativa federal, tem sido observada, uma vez que governos estaduais tem utilizado uma técnica interessante para burlar a legislação administrativa de tutela ambiental: expedem-se atos normativos autorizando o plantio indiscriminado de florestas de eucalipto (silvicultura) sem exigência de estudos de impactos ambientais e seus respectivos relatórios (art. 48, da Resolução Secretaria Estadual do Meio Ambiente e Desenvolvimento Econômico (Semade/MS n. 9,9 (de 13/05/2015)), muito embora o art. $2^{\circ}, \S 1^{\circ}$ da referida Resolução Conama 237/97 (nacionalmente válido) apresente previsão expressa em sentido contrário.

Nessa perspectiva, é possivel inferir que há, de fato, toda uma política pública, nas três esferas do sistema federativo (federal, estadual e municipal) voltada a atrair investimentos, principalmente, privados, sem descuidar dos vastos valores investidos via Banco Nacional de Desenvolvimento Econômico e Social (BNDES) nos projetos capitalistas ali. Em geral, inicia-se com políticas de isenções tributárias de longo prazo que causam intenso impacto nas finanças públicas, já que, principalmente, as normas criadas com tal escopo impedem que haja arrecadação por parte de todo um setor produtivo - no caso, o complexo celulose-papel, em princípio, mas não somente.

A continuidade desse processo de expropriação privada de recursos naturais e públicos leva à cessão de áreas por parte da municipalidade destinadas à instalação dos complexos industriais e, também, à criação de alojamentos destinados a receber a mão-de-obra que deve criar e manter o parque industrial. Além disso, nota-se, com veemência, que até mesmo a legislação ambiental é alterada, ou, ignorada, com o fito de acomodar-se às exigências do capital industrial (veja-se a respeito que o Governo do Mato Grosso do Sul, por meio de resolução da Secretaria de estado de Meio Ambiente, das Cidades, do Planejamento, da Ciência e Tecnologia violou, frontalmente, a Resolução Conama 237/1997, dispensou o complexo celulose-papel - silvicultura - da obrigação de realizar e apresentar estudos de impactos

\footnotetext{
Veracel. s. d. Acessado em 8 abr. 2017, http://www.veracel.com.br/default.aspx?tabid=111).

Eldorado Brasil. s. d., acessado em 8 abr. 2017, http://www.eldoradobrasil.com.br/Paginalnterna.aspx?idPage=7

Fibria. s. d. Acessado em 8 abr. 2017, http://www.fibria.com.br/web/pt/negocios/floresta/matogrosso.htm.

Conselho Nacional do Meio-ambiente - Conama. s. d., acessado em 8 abr. 2017, https://www.icmbio.gov.br/cecav/images/download/CONAMA\%20237_191297.pdf.

9 LegisWeb. 2015, acessado em 10 abr. 2017, https://www.legisweb.com.br/legislacao/?id=284742.
} 
ambientais e seus respectivos relatórios).

Como um dos resultados empíricos avistados tem-se o aparelhamento de um estado fraco em detrimento de uma ação social forte por parte dos investidores e seus agentes. Um estado fraco, seja na área federal, estadual, ou, principalmente, municipal, tende a gerar situações em que os conflitos sociais sejam invisibilizados, principalmente, quando o tema central em questão é o ambiente, bem jurídico difuso, cuja titularidade nem sempre é passivel de ser identificada de plano. O tom, portanto, dessa sinfonia macabra é avassalador, do ponto de vista da simbiose capital-estado/ privado-público/assistencialismo-autonomia e de como se criam, sustentam, legitimam e oferecem condições para a ampliação desmedida da ideia de que terra é poder e, território, locus de conquista, tudo feito em nome do progresso, do desenvolvimento e da sustentabilidade em detrimento de uma maior participação democrática da sociedade, como um todo, no bolo de renda, urbana e principalmente, fundiária.

A concentração de terras, isto é, a manutenção dos latifúndios pré-existentes e a criação de novos com a compra e/ou o arrendamento de porções significativas de áreas rurais pelas indústrias, bem como, o número reduzido de atores atuantes no mercado nacional de celulose-papel é da essência do modelo e da forma como ele se introduziu no Brasil. Sabe-se que "desde a sua concepção, o número de empresas participantes do mercado fica sujeito à política de escala mínima do BNDES. Assim, a indústria de celulose já nasceu oligopolizada" (Montebello e Bacha citados em Schlesinger 2008, 68) e financiada pelo próprio estado, o que revela um contrassenso a tudo o que vem sendo propagado - e propagandeado - pelos agentes do complexo agroindustrial territorial eucalipto-celulose-papel no que respeita a suas reais capacidades de geração de renda e empregabilidade.

Fato relevante a se destacar e explicitado por Kudlavicz é que foi justamente por meio desse progresso alardeado, das concessões de créditos e beneficios fiscais por parte do estado e dos programas criados para ocupação inconteste do Centro-Oeste pela agroindústria que se acabou por cunhar a expressão e o sentimento de que a microrregião de Três Lagoas tinha uma vocação florestal (Kudlavicz 2011, 48), que restou incorporada pelo senso comum. Nesse sentido, o mito do progresso e o mantra da prosperidade para todos se apresentam como duas partes do grande motor da civilização e as suas vinculações ao poder são inegáveis, bem como, a ideia de que o progresso não é neutro, mas, "a quem dominantemente [...] serve e quais os riscos e custos de natureza social, ambiental e de sobrevivência da espécie que ele está provocando; e que catástrofes futuras ele pode ocasionar" (Dupas 2012, 27).

Trata-se, portanto, da necessidade de se problematizar o que é progresso, a quem ele beneficia, em que condições ele é visualizado e quais os motivos para a sua aceitabilidade/visualização?

Uma das perspectivas possiveis é ancorar essa investigação numa análise socioeconômica tradicional. Por ela, o que se vê ocorrer na região do Bolsão nada mais é do que fruto da evolução humana, isto é, do desencadear de processos inexoráveis que tendem a buscar condições materiais que possam oferecer melhores situações de vida ao maior número possivel de pessoas envolvidas. Mas, sob outro aspecto, que busca retratar a história não ortodoxa, ou seja, as vivências dos vencidos (Löwy 2005, 10-11), é possivel realizar um resgate e, ao mesmo tempo, explicitar fatores e situações concretas de vida que contrapõem o discurso da racionalidade hegemônica do capitalismo, de forma a buscar dar visibilidade a uma parcela consideravelmente mais ampla de pessoas que nada obtém de beneficios ante a presença do modelo e, pior, são expropriadas, sistematicamente, tendo por matriz a ideia de que essa expropriação custosa, dolorosa, degradante e desumana está na ordem do dia de uma conduta de vida que visa ao sucesso (Martins 1981, 147-148).

Ainda que não se pretenda que o estado possa acompanhar a vertiginosa escalada dos investimentos privados, interessa perceber que investimentos em setores como segurança pública, saúde, lazer, educação e habitação não correspondem à expansão industrializante, podendo tornar-se vetores de violência como se pode 
perceber na região de Três Lagoas, MS (entre os entrevistados, doze entre treze sujeitos declararam que certa sensação de insegurança se encontrava presente e que percebiam que a violência na cidade e região havia se elevado ao longo da última década). Some-se a isso a concentração fundiária e econômica, a migração indiscriminada de mão de obra e o fluxo de capital como mais um chamativo à movimentação de parte da criminalidade, organizada ou não, bem como, o fato de se criar como que uma espécie de paraíso ambiental [no sentido pejorativo do termo] com a dispensa de Estudo de impactos ambientais e Relatório de impactos ambientais (EIA-Rima, respectivamente ao setor agricultável de silvicultura que, assim, fica à margem do sistema jurídico de controle, administrativo e até penal, com problemas estruturais que não conseguem, sequer, ser mitigados - abarrotamento do Sistema Único de Saúde (SUS), elevação dos índices de violência, poluição ambiental, expropriação de água, depauperação dos recursos naturais e humanos, subjugação dos assentamentos de reforma agrária aos interesses e prazos impostos pelo complexo agroindustrial territorial eucalipto-celulose-papel. ${ }^{10}$

O que se evidencia, pela pesquisa, neste artigo, é que a noção de progresso é extremamente discutivel e pouco defensável, na linha da expropriação capitalista frente ao diálogo com os direitos humanos e que o mantra da prosperidade é definitivamente falso, pois, atende a uma minoria frente à dimensão populacional afetada e, ainda, tende a manter, indefinidamente, o perverso lado da exclusão social dos mais fracos no sistema.

\section{Um projeto de reforma agrária no bolsão sul-mato-grossense}

O local escolhido para a pesquisa qualitativa é originário de uma ação social, um movimento camponês espontâneo desencadeado por agricultores familiares sem-terra da região do Bolsão, borda Leste do Mato Grosso do Sul, entre 2008 e 2009, sobre uma fazenda improdutiva, e que, ao findar do tempo e das lutas, com invasões, permanência no local e persistência dos atuais assentados, principalmente, que culminou na divisão da área em 181 (cento e oitenta e um) lotes desapropriados pelo Incra e cedidos para a reforma agrária, cujo processo de assentamento efetivo deu-se em 2009, curiosamente, ano de entrada em operação de uma das papeleiras ali. O ano de 2009 foi extremamente funesto para os assentados, visto a condição precária do acesso à água naquele local, pois, apenas a antiga sede da fazenda era provida. Pode-se falar de um verdadeiro confinamento imposto aos assentados durante esses primeiros doze meses.

A condição constatada em julho de 2015, que se mantém até agora, pouco melhorou, com a instalação de um reservatório para a água, com capacidade de 20 mil litros em armazenagem e instalação de uma rede de distribuição precária, feita com recursos federais e muito mal executada pela empresa vencedora da licitação, o que, até hoje, se traduz em problemas e problemas no acesso e distribuição de água pelos lotes.

A partir de fins de 2013, uma das papeleiras iniciou estudos para implantação de mais dois reservatórios, com capacidade individual de 30 mil litros cada, orçados em R\$ 87.000,00, o que elevaria a capacidade de abastecimento para 80 mil litros d'água. Todavia, isso ainda não se operou e o assentamento persistiu com meros 20 mil litros d'água, o que inviabiliza uma produção agrícola minimamente constante e, mesmo, atender às necessidades humanas dos 181 assentados e suas familias, até meado de 2018. A partir de julho/2018 uma das papeleiras alterou seu modus operandi para com o assentamento e metade dos assentados, tendo perfurado 90 (noventa) poços semiartesianos naquele local, gradativamente, operação que adentrou o ano de 2019 até seu fim.

\section{Cativeiros de papel}

Durante os trabalhos de campo, uma informação colhida em entrevista no assentamento, localizado na região de Três Lagoas foi que a Agraer, agência que deveria prover aos assen-

10 Almeida, Rosemeire Aparecida de. 2012. A nova fronteira do eucalipto e a crise da reforma agrária. Boletim Dataluta, 1: 2-10, acessado em 3 jan. 2018, http://www2.fct.unesp.br/nera/boletimdataluta/boletim_dataluta_12_2012.pdf. 
tados assistência técnica em extensão rural, na verdade, não cumpria essa função, atuando, muito mais, como uma espécie de agente censor/ fiscalizador do Incra, tendo sido noticiado que muitos assentados estavam sendo pressionados por nada produzirem, quando, em verdade, não o poderiam, tanto por escassez de água, como, por não terem conseguido, ainda, limpar a área, isto é, realizar o desmate exigido por ausência de plano de manejo prévio (que poderia e deveria ser fornecido pela própria Agraer).

Assim, o Incra não confere o certificado de cessão de uso (CCU), porque vários assentados não davam, nem dão conta de cumprir a obrigação inicial - limpar o lote, realizando o desmate mínimo, mediante plano de manejo prévio - e a Agraer não prestava a assistência devida porque esses mesmos assentados não tinham o tal CCU. Sem o CCU, nada é possível, em termos legais, aos assentados; nenhum financiamento, nenhuma assistência por parte dos órgãos públicos oficiais. Evidenciou-se, aqui, o ponto nevrálgico do conflito socioambiental ali: a ausência, proposital, ou, não, de regularidade da área rural cedida pelo Incra imobilizava muitos assentados, impedindo-os de produzir e, assim, cumprir sua função social por meio da agricultura familiar e sobreviver.

Veja-se o imbróglio: o Incra não fornece o CCU porque assentados não cumpriram as obrigações iniciais exigidas no ato de imissão na posse dos lotes, ou seja, realizar a limpeza da área mediante desmate; a Agraer, que deveria oferecer a assistência técnica em forma de plano de manejo para o desmate não atende aos assentados porque esses não dispõem de regularidade fundiária, o tal CCU. É um círculo vicioso, o mais perverso por atingir, justamente, assentados pelo próprio Incra, gente despossuída, sem recursos, sem condições de contratar uma consultoria que supra a omissão da Agraer, para dar conta de regularizar-se mediante o plano de manejo e o efetivo desmate legal.

Enquanto o complexo territorial eucalipto-celulose-papel, na expressão de Almeida ${ }^{11}$ é isento pelo estado de MS de licenciar suas operações em campo, diga-se "florestais", beneficiando-se à larga com créditos e financiamentos, especialmente subsidiados e com carência para início do pagamento, pelo FCO ou pelo BNDES, principalmente, além de receber isenções fiscais de tributos estaduais e municipais, apenas no assentamento de reforma agrária, vários agricultores familiares são impedidos de produzir e correm risco, até, de reversão das posses pelo Incra, por não cumprirem sua função social pela absoluta ausência do CCU, documento preliminar de regularização fundiária e de acesso a qualquer financiamento, público ou privado. A matriz de Justiça Ambiental se encaixa, bem, nesse conflito.

Emerge desse drama social, como única alternativa de financiamento da produção familiar, a submissão aos planos e programas de desenvolvimento sustentável propostos pelas indústrias papeleiras. Assim, nesse sentido, assentados que queiram, ou necessitem de financiamento para produzir, devem se postar sob o jugo de uma ou de ambas as papeleiras, que se constituiram na única fonte de recursos ali, face ao impedimento que a ausência de CCU impõe aos assentados para buscarem recursos em instituições bancárias, públicas ou não. Criou-se, então, ao que parece, uma relação assistencialista que não visa a romper com a condição de dominação dos assentados pelo capital industrial, muito ao contrário e que preserva um status de subserviência por meio do assistencialismo, limitando a agricultura familiar e, ao mesmo tempo, dirigindo as potencialidades dos assentados e do assentamento, como um todo. Essa percepção ficou muito evidente quando, ao findar da entrevista, convidaram o pesquisador a conhecer um dos projetos, que combinava a criação de galinhas em regime de semicativeiro com horta orgânica e fruticultura, financiado por uma das indústrias papeleiras, a Eldorado Brasil. ${ }^{12}$

\footnotetext{
11 Almeida, Rosemeire Aparecida de. 2012. A nova fronteira do eucalipto e a crise da Reforma Agrária. Boletim Dataluta, 1: 2-10, acessado em 3 jan. 2018, http://www2.fct.unesp.br/nera/boletimdataluta/boletim_dataluta_12_2012.pdf.

12 Fibria Celulose S. A. 2014. Relatório de Sustentabilidade, acessado em 7 jul. 2017, http://www.eldoradobrasil.com.br/img/Relatorio_de_Sustentabilidade_2014.pdf.
} 
Figura 1 - Programa de Produção Agroecológica Integrada e Sustentável - Pais, projeto de criação de galinhas de granja em semicativeiro integrado à horta agroecológica e fruticultura, financiado pela Eldorado Brasil

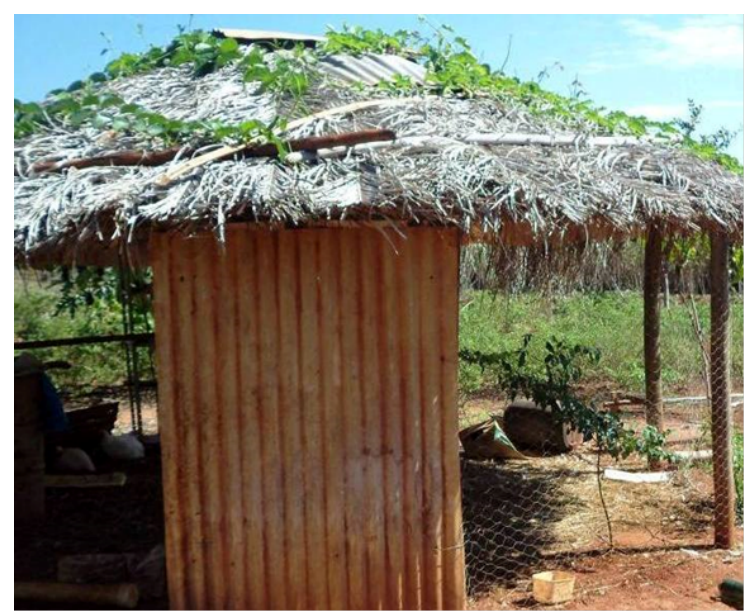

Fonte: Elaboração dos autores (2015).

O projeto em questão decorre de compromissos firmados pela indústria em seus contratos de financiamento junto ao BNDES. Há cláusulas que obrigam ao investimento de certo percentual do crédito obtido em ações sociais. No caso destacado, essa indústria optou por atender a alguns assentados do assentamento, propondo alternativas de produção de renda. Colheu-se de assentado o seguinte relato: os assentados não foram ouvidos se esse seria um projeto de interesse prá nós (Assentado 1, com. pess. 24 de julho de 2015), ou seja, se seria compativel com as suas capacidades, ou, se teriam interesse, ou, mesmo interessados, como se daria o projeto, o que resultou na obrigação de aceitar um modelo pronto-e-acabado, com galinhas de granja, cujo resultado se revelou pífio face à pouca ou nenhuma rusticidade dessa espécie para o tipo de criação a que se propôs.

Se é possivel contribuir com alguma problematização e crítica, neste trabalho, sobre o referido programa, pode-se afirmar que o fato de que se distribuiu, em cerimônia realizada na sede do Serviço Brasileiro de Apoio às Micro e Pequenas Empresas (Sebrae) em Três Lagoas, apenas 35 (trinta e cinco) kits (dez outros já haviam sido distribuidos anteriormente, em 2013, entre Três Lagoas e Selvíria, pela mesma indústria). Tem-se, então, 45 (quarenta e cinco) lotes/assentados beneficiados pelo País, mas, apenas no assentamento são mais de cento e oitenta candidatos ao referido programa. Logo, a iniciativa se revela muito mais pirotécnica, isto é, para fazer barulho, causar publicidade do que algo efetivo, concreto, que realmente vá mudar a realidade dos assentados. Por outro lado - e aqui a crítica deve ser mais contundente - esse tipo de apoio, prestado pela indústria por conta de compromissos firmados e exigências para alcançar os financiamentos do BNDES, sem a parceria e presença direta do estado, via Incra e/ou Agraer, acaba por lançar os assentados numa completa relação de submissão e subserviência que, ao invés de promover a libertação do cativeiro capitalista, os mantém sob o jugo do assistencialismo do capital industrial e sob o crivo do tempo social ditado pelas papeleiras.

Entende-se por cativeiro, no caso, a condição a que foram submetidos os assentados, sujeitos da pesquisa, os quais aguardavam, com a posse da terra, libertar-se do jugo exploratório, com base na renda da terra, mas, viram-se impossibilitados disso mediante o assistencialismo das indústrias conjugado com a ausência do Estado, estando subjugados pelos limites e pelo tempo social imposto pelo complexo agroindustrial territorial eucalipto-celulose-papel. Nessa perspectiva, comprova-se uma nova ferramenta de controle social por parte da relação simbiótica capital/ estado: este último se mantém inerte, principalmente, por seus órgãos como Incra, Agraer, Ibama, ou, realizando funções aparentes quanto ao licenciamento ambiental, caso do Imasul, cujas chancelas aos grandes empreendimentos parecem habituais, quase de ofício; ao mesmo tempo, o capital agroindustrial adota os assentados, colocando-se como única fonte e perspectiva de financiamento de projetos para produção da agricultura familiar. Entretanto, os projetos não podem ser destinados a todos; há aqueles que - ainda - não conseguiram o documento mínimo para regularização fundiária, isto é, o certificado de cessão de uso (CCU). Por outro lado, mesmo para os que se encontram regularizados, os pro- 
jetos e financiamentos, aparentemente, dão-se em doses ultra-homeopáticas, contemplando parcos agricultores a cada ano, de forma que o assistencialismo - e o cativeiro - seja mantido por longo período. Quanto à outra indústria, Fibria (atualmente Suzano), também essa desenvolve projetos sociais na região do Bolsão, em moldes semelhantes aos da sua concorrente, beneficiando a assentados rurais, população urbana de Três Lagoas e região e, até, aldeia indigena localizada na área rural de Brasilândia.

Figura 2 - Perfuração do poço e instalação de reservatório de 30 mil litros Assentamento 20 de Março, Três Lagoas, MS

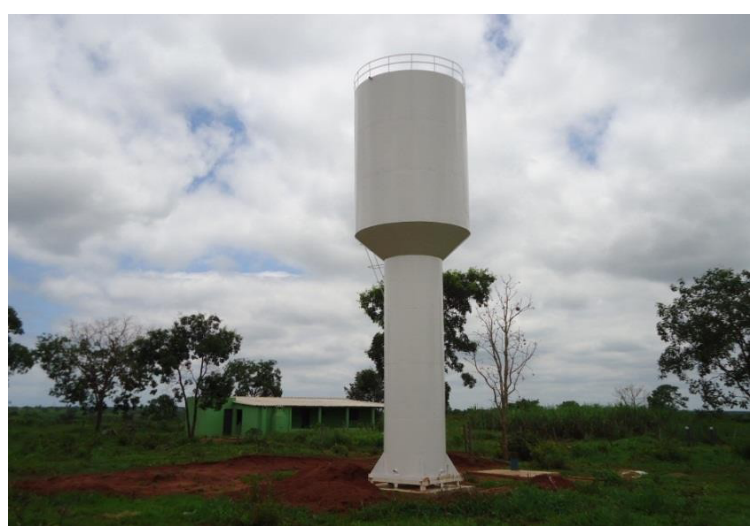

Fonte: Fibria, Relatório Destaques MS 2015 (2015).

Figura 3 - Construção do Centro Comunitário do Assentamento São Joaquim, em Selvíria, MS

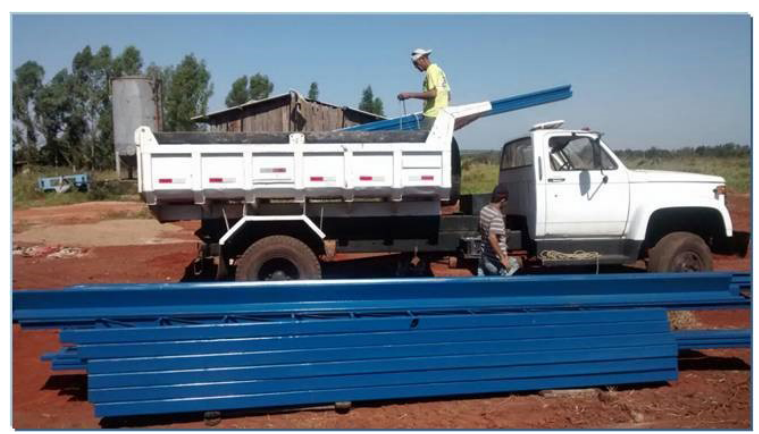

Fonte: Fibria, Relatório Destaques MS 2015 (2015).

O relatório citado (Destaques MS 2015) apresenta muitos outros projetos sociais desenvolvidos pela Fibria, atual Suzano, junto a outros agricultores familiares, assentados, comunidade indigena, populações urbanas etc. Pelo momento optou-se por explicitar apenas dois projetos, exemplificativamente, o que não é feito com o fito de diminuir a demonstração de investimentos sociais realizados por essa indústria, mas, apenas, registrar o suficiente sobre tais investimentos e projetos, para o que interessa a este trabalho. A existência de vários projetos sociais, no sentir da pesquisa, tem o condão de demonstrar a ausência estatal em detrimento da forte presença do capital agroindustrial. É nessa perspectiva que se fala neste trabalho da formação dos cativeiros de papel pelos desertos verdes.

Ressalte-se que se extraiu da empiria, em que 12 (doze) atores sociais foram entrevistados e responderam a questionários, além da entrevista em si, uma sensação quase generalizada de que não existiriam conflitos ambientais, sociais, econômicos, propriamente ditos. Onze sujeitos da pesquisa acreditavam no mantra da prosperidade infinita e do desenvolvimento sustentável, mesmo diante de declarações deles próprios no sentido de uma sensação de elevação dos índices de criminalidade, abandono do campo pelos proletários rurais, dificuldades em operacionalizar a agricultura, pecuária, especialmente sob o modelo familiar, ausência de investimentos e apoio por parte dos órgãos e agências estatais. Em sintese, a empiria demonstrou uma certa ausência de consciência de classe em grande parte dos sujeitos da pesquisa, os quais relatam os conflitos socioambientais como meros problemas, quando muito, o que dificulta não apenas o seu enfrentamento, como, também, a própria condição de seu tempo social, uma vez que, acabam por restringir seu inconformismo dentro de uma esfera da vida privada, não havendo dinamização da luta para o efetivo enfrentamento da condição em que se encontram: os cativeiros de papel.

\section{Considerações finais}

A entrada em operação das duas maiores indústrias de pasta de celulose do mundo na região de Três Lagoas deflagrou uma nova época para a vertente da concentração fundiária. A par disso, esse modelo monocultural passou a exercer, por meio da concentração fundiária e econômica, o monopólio dos investimentos, públicos e privados 
naquela região, denominada Bolsão Sul-mato- grossense. Nesse sentido, frente à ausência de investimentos públicos para a realização de uma reforma agrária concreta, os assentados viram-se à mercê dos programas de desenvolvimento social praticados pelas duas papeleiras instaladas naquela região. Os desertos verdes não apenas se instalaram causando forte pressão sobre a agricultura familiar, como, também e principalmente, passaram a controlá-la, pois, as papeleiras se apresentam como única fonte de recursos viável para os assentados. Diante disso uma das grandes questões que se posta é evidenciar que o modelo negocial proposto na região do Bolsão Sul-mato-grossense envolve a simbiose entre o público e o privado que privilegia a acumulação do capital e, num contexto bastante favorável às indústrias, ante a omissão dos órgãos estatais, como o Incra e a Agraer, mantém os assentados, no caso, aqueles sujeitos da pesquisa, do assentamento onde se deu a empiria numa relação de exclusiva dependência dos projetos de desenvolvimento sustentável ofertados e geridos pelas duas grandes papeleiras ali, o que passamos a denominar por cativeiros de papel.

\section{Referências}

Acselrad, Henri. 2004. As práticas espaciais e o campo dos conflitos ambientais. In Conflitos ambientais no Brasil, organizado por Henri Acselrad, 13-35. Rio de Janeiro: Relume Dumará - Fundação Heinrich Böll.

Brandão, Carlos. 2010. Acumulação primitiva permanente e desenvolvimento capitalista no Brasil contemporâneo. In Capitalismo globalizado e recursos territoriais: fronteiras da acumulação no Brasil contemporâneo, organizado por Alfredo Wagner Berno Almeida, 39-69. Rio de Janeiro: Lamparina.

Costa, Heloisa Soares de Moura e Tânia Moreira Braga. 2004. Entre a conciliação e o conflito: dilemas para o planejamento e a gestão urbana e ambiental. In Conflitos ambientais no Brasil, organizado por Henri Acselrad, 195-216. Rio de Janeiro: Relume Dumará - Fundação Heinrich Böll.

Dupas, Gilberto. 2012. O mito do progresso, ou progresso como ideologia. 2 ed. São Paulo: Editora Unesp.

Furtado, Celso. 1974. O mito do desenvolvimento econômico. São Paulo: Paz e Terra.

Harvey, David. 2014. O novo imperialismo. 8 ed. São Paulo: Edições Loyola.
Kudlavicz, Mieceslau. 2011. Dinâmica agrária e a territorialização do complexo celulose/papel na microrregião de Três Lagoas-MS. Dissertação em Geografia, UFMS, Três Lagoas.

Leff, Enrique. 2006. Racionalidade ambiental: a reapropriação social da natureza. Rio de Janeiro: Civilização Brasileira.

Lopes, José Sergio Leite. 2004. A ambientalização dos conflitos em Volta Redonda. In Conflitos ambientais no Brasil, organizado por Henri Acselrad, 217-244. Rio de Janeiro: Relume Dumará - Fundação Heinrich Böll.

Löwy, Michael. 2005. Walter Benjamin: aviso de incêndio: uma leitura das teses "Sobre o conceito de história". São Paulo: Boitempo.

Martínez Alier, Joan. 2014. O ecologismo dos pobres: conflitos ambientais e linguagens e valoração. 2 ed. São Paulo: Contexto.

Martins, José de Souza. 1981. O cativeiro da terra. 2 ed São Paulo: Lech.

Marx, Karl. 1987. O capital: critica da economia politica Livro Terceiro: o processo global da produção capitalista. v. IV. 5 ed. Rio de Janeiro: Difusão Editorial.

Paulani, Leda. 2008. Brasil delivery: servidão financeira e estado de emergência econômico. São Paulo: Boitempo.

Porto Gonçalves, Carlos Walter e Danilo Pereira Cuin. 2013. Geografia dos conflitos por terra no Brasil (2013): expropriação, violência e r-existência. In Conflitos no campo - Brasil, 2013, coordenado por Antônio Canuto, Cássia Regina da Silva Luz e Flávio Lazzarin, 18-26. Goiânia: CPT Nacional - Brasil.

Santos, Milton e Maria Laura Silveira. 2002. O Brasil: território e sociedade no início do século 21. 4 ed. Rio de Janeiro: Record.

Schlesinger, Sergio. 2008. Lenha nova para velha fornaIha: a febre dos agro-combustiveis. Rio de Janeiro: Fase.

Scotto, Gabriela e Angela Ramalho Vianna. 1997. Conflitos ambientais no Brasil: natureza para todos ou somente para alguns? Rio de Janeiro: Ibase.

\section{Cláudio Ribeiro Lopes}

Doutor em Ciências Jurídicas e Sociais pela Universidade Federal Fluminense (UFF), Niterói, RJ, Brasil. Docente e pesquisador na Universidade Federal do Mato Grosso do Sul (UFMS), campus de Três Lagoas, MS, Brasil.

\section{Napoleão Miranda}

Doutor em Sociologia pelo Instituto Universitário de Pesquisas do Rio de Janeiro (luperj), Rio de Janeiro, RJ, Brasil. Professor da Universidade Federal Fluminense (UFF), Niterói, RJ, Brasil. 